\title{
Prevention of Intracranial In-stent Restenoses: Predilatation with a Drug Eluting Balloon, Followed by the Deployment of a Self-Expanding Stent
}

\author{
Zsolt Vajda $\cdot$ Thomas Güthe $\cdot$ Marta Aguilar Perez \\ Wiebke Kurre · Elisabeth Schmid • Hansjörg Bäzner • \\ Hans Henkes
}

Received: 14 March 2012/ Accepted: 20 June 2012/Published online: 7 August 2012

(C) Springer Science+Business Media, LLC and the Cardiovascular and Interventional Radiological Society of Europe (CIRSE) 2012

\begin{abstract}
Purpose Stenting in intracranial atherosclerotic disease (ICAD) is increasingly debated, due to issues of procedural safety, technical efficacy, and in-stent recurrent stenoses (ISR). In the present study, feasibility, safety, and efficacy of angioplasty using a drug-eluting balloon (DEB) followed by the implantation of a self-expanding stent (Enterprise) were evaluated for the treatment of ICAD lesions.

Methods Fifty-two patients (median age: 71 years; range: 54-86 years; male/female ratio 37:15) underwent stenting of high-grade ICAD lesions between February 2010 and
\end{abstract}

Z. Vajda $\cdot$ T. Güthe $\cdot$ M. A. Perez $\cdot$ W. Kurre $\cdot$ H. Henkes $(\bowtie)$ Klinik für Neuroradiologie, Neurozentrum, Klinikum Stuttgart, Katharinenhospital, Kriegsbergstrasse 60, 70174 Stuttgart, Germany

e-mail: hhhenkes@aol.com

Z. Vajda

e-mail: Z.Vajda@klinikum-stuttgart.de

T. Güthe

e-mail: T.Guethe@klinikum-stuttgart.de

M. A. Perez

e-mail: M.Aguilar@klinikum-stuttgart.de

W. Kurre

e-mail: w.kurre@klinikum-stuttgart.de

E. Schmid · H. Bäzner

Klinik für Neurologie, Neurozentrum, Klinikum Stuttgart,

Stuttgart, Germany

e-mail: ESchmid@klinikum-stuttgart.de

H. Bäzner

e-mail: H.Baezner@klinikum-stuttgart.de

H. Henkes

Medizinische Fakultät der Universität Duisburg-Essen,

Essen, Germany
November 2011 in a single center. Angioplasty using a paclitaxel coated SeQuent Please (B. Braun, Germany) or DIOR (Eurocor, Germany) coronary PTCA balloon, followed by the implantation of a self-expanding stent (Enterprise, Codman, USA) was performed in 54 lesions. Angiographic and clinical follow-up was performed at 6 and 12 weeks, 6 and 12 months, and yearly thereafter. Technical success rate, periprocedural complications, occurrence of recurrent ischemic symptoms, and the development of an ISR were analyzed.

Results Angioplasty using a DEB followed by stent implantation was successfully performed in $44(81 \%)$ cases. DEB insertion failed in $19 \%$ of the cases and angioplasty was finally performed using a conventional PTCA balloon. The combined procedure related permanent neurologic morbidity and mortality rate (stroke, $\mathrm{ICH}$, and subarachnoid hemorrhage) at 30 days and beyond was $5 \%$. Angiographic and clinical follow-up were obtained in 33 (61\%) lesions in 32 patients. Recurrent stenosis was seen in one $(3 \%)$ lesion.

Conclusion Angioplasty and stenting using a DEB is safe and yields encouragingly low ISR rates. Further technical developments to improve lesion accessibility are, nevertheless, mandatory.

Keywords Neurointerventions - Arterial intervention . Angioplasty/angiogram

\section{Introduction}

Intracranial atherosclerotic disease (ICAD) is responsible for at least $8-10 \%$ of cerebral ischemic strokes [1]. Medical therapy alone does not provide sufficient protection against ischemic stroke in patients with symptomatic 
intracranial stenotic lesions. In the Warfarin-Aspirin Symptomatic Intracranial Disease (WASID) study, the 2-year rate of ischemic stroke in patients with symptomatic ICAD and on high-dose aspirin medication was $19.7 \%$ [2]. The recently published data from the prematurely halted SAMMPRIS trial, which evaluated whether intracranial angioplasty combined with stenting using the Wingspan system adds benefit to aggressive medical therapy alone for preventing stroke in patients with ICAD, showed a 1-year stroke probability rate of $12.2 \%$ in the territory of the affected artery despite aggressive medical-management [3]. In the same trial, percutaneous angioplasty and stenting of symptomatic high-grade intracranial stenoses using the Wingspan stent was performed with a surprisingly high, $14.7 \% 30$-day stroke rate and a $20 \% 1$-year probability of stroke in the territory of the affected vessel. Recurrent strokes resulting from in-stent recurrent stenoses (ISR), however, were not yet considered in this estimation, although recurrence rates as high as $31 \%$ have been reported previously with the Wingspan stent $[4,5]$.

The use of balloon mounted drug-eluting coronary stents in ICAD showed promising results with recurrence rates as low as $3.9 \%$. These devices however proved to be too rigid for intracranial application in patients with tortuous supra-aortic and intracranial vasculature and resulted in relatively high rates of failed treatment attempts between 4 and $14 \%$ [6]. Angioplasty using a properly selected conventional PTCA balloon followed by the implantation of a self-expanding bare metal stent, on the other hand, can be performed even in lesions of distal segments of intracranial arteries in almost any anatomical situation, but at the cost of the above-mentioned high ISR rates of 24-31\% [5, 7].

Recently, encouraging results have been published for the reangioplasty of intracranial ISR lesions using a paclitaxel eluting PTCA balloon, which proved to be more than fivefold effective in the prevention of ISR compared with conventional balloons [8]. The purpose of the present study was to evaluate the feasibility, procedural safety, and stroke prevention efficacy of a modified angioplasty and stenting protocol, using a paclitaxel-eluting PTCA balloon for angioplasty, followed by the implantation of a selfexpanding neurovascular stent (Enterprise).

\section{Methods}

\section{Patient Selection}

The present series comprised 52 consecutive patients who underwent elective endovascular treatment of 54 significant $(\geq 50 \%)$ intracranial atherosclerotic arterial stenoses in the period from February 2010 to November 2011 in a single institution by or under the supervision of the senior author, according to identical principles of pre-, per-, and postprocedural management.

Endovascular treatment by angioplasty with the paclitaxel coated SeQuent Please (B. Braun, Berlin, Germany) or Dior (Eurocor, Bonn, Germany) coronary PTCA balloon followed by the implantation of the self-expanding Enterprise stent (Codman \& Shurtleff, Raynham, MA) was offered to patients with a symptomatic or progressive intracranial stenotic lesion or if the affected vascular territory had no sufficient collaterals (multivessel disease). Endovascular treatment also was offered for lesions that were discovered during the pretreatment angiography during the endovascular treatment of a symptomatic intraor extracranial stenotic lesion. The above mentioned lesions are considered to carry an increased risk of subsequent cerebral ischemia $[9,10]$. Failure of previous medical therapy was not a compulsory indication criterion for the endovascular treatment.

The treated lesions were located on the extra- and intradural internal carotid artery (ICA), the middle cerebral artery (MCA), the intradural vertebral artery (VA), or the basilar artery (BA). Excessive atherosclerotic tortuosity and major caliber difference of the target vessel proximal and distal to the stenotic segment were considered as contraindications for the use of the rather rigid drug-eluting angioplasty balloon.

All patients were explicitly informed and gave informed consent to the off-label intracranial use of the coronary drug-eluting balloon and the off-label use of the Enterprise stent for the treatment of stenotic lesions, because this stent is certified for intracranial use in the setting of stentassisted coiling of cerebral aneurysms. Further details on the legal aspects on off-label use of medical devices within the German jurisdiction are given elsewhere [6].

\section{Procedures}

Patients included in the study were examined by an independent neurologist before and after the endovascular treatment and were administered a dual platelet anti-aggregation regime with a loading dose of $500 \mathrm{mg}$ of acetylsalicylic acid (ASA) and $600 \mathrm{mg}$ of clopidogrel given at least 1 day before the treatment, followed by $100 \mathrm{mg}$ of ASA and $75 \mathrm{mg}$ of clopidogrel daily for at least 1 year, and $100 \mathrm{mg}$ of ASA daily thereafter. The endovascular procedures were performed under general anesthesia using a $6 \mathrm{~F}$ or $8 \mathrm{~F}$ guiding catheter. Intraprocedural medication included 5,000 U of intravenous heparin, $500 \mathrm{mg}$ of intravenous ASA, and $2 \mathrm{mg}$ of intraarterial glycerintrinitrate through the guiding catheter for the prevention of mechanically induced vasospasm.

Stenosis grade, length, and normal vessel diameter of the target lesion were determined and the vessel distal to the stenosis was catheterized with a SilverSpeed-14 (Covidien/ev3, Irvine, CA) or a Traxcess14 (Terumo 
Medical Corporation, Somerset, NJ) microguidewire under roadmap guidance.

The diameter of the drug-eluting balloon (DEB) was selected to correspond to approximately $80 \%$ of the diameter of the normal vessel. Predilatation with a smaller diameter (1.0-1.5 mm) balloon (Ryujin Plus, Terumo Medical Corporation, Somerset, NJ) was performed in high-grade lesions to facilitate the advancement of the more rigid DEB over the lesion. Balloons were slowly inflated at nominal pressures (i.e., Ryujin Plus: 6 atm, SeQuent Please: 7 atm, Dior: 6 atm) using a manometer, and DEBs were left inflated for $60 \mathrm{~s}$ to allow for the transition of the paclitaxel from the balloon surface into the vessel wall. After deflation and withdrawal of the DEB, a flushed $0.021 \mathrm{in.} \mathrm{ID} \mathrm{microcatheter} \mathrm{(RapidTransit} \mathrm{or}$ Prowler Select Plus, Codman \& Shurtleff, Raynham, MA) was inserted over the exchange wire. Following the removal of the microguidewire an Enterprise stent (Codman) with a nominal diameter of $4.5 \mathrm{~mm}$ and a length of $14,22,28$, or $37 \mathrm{~mm}$ was centered over the lesion and deployed. During the first days after the procedure systolic blood pressure was maintained strictly at $\leq 130 \mathrm{mmHg}$. All patients underwent MRI and clinical assessment prior to discharge. Angiographic follow-up and neurological examination with emphasis on intermittent ischemic events was performed at 6 weeks, 12 weeks, 6 months, and 12 months following the procedure and yearly thereafter.

\section{Results}

A total of 52 patients (median age: 71 years; age range: 54-86 years; male-to-female ratio: $37: 15)$ with $n=54$ intracranial atherosclerotic lesions were included in this study. Lesion locations were as follows: ICA extradural $(n=2,4 \%)$, ICA intradural $(n=5,9 \%)$, MCA $(n=13$, $24 \%)$, intradural VA $(n=18,33 \%)$, and BA $(n=16$, $30 \%)$. The distribution of the lesions within intradural and extradural vessel segments was $52(96 \%)$ and $2(4 \%)$, respectively.

Of the 54 lesions, 6 (11\%) were asymptomatic and were originally identified on the preprocedural angiographic images at the treatment of a symptomatic high-grade lesion of another intracerebral artery, and 45 (83\%) were symptomatic (TIA, stroke or silent infarcts in the supply area of the affected vessel). There was one rapidly progressive lesion of the V4 segment of the left vertebral artery found on the follow-up angiography following a thrombectomy of the basilar artery with a lumen reduction of $83 \%(n=1,1.8 \%)$. There was an extradural stenotic lesion of the right ICA with a luminal reduction of $57 \%$, detected during the treatment of a symptomatic high-grade stenotic lesion of the right MCA $(n=1,1.8 \%)$. Finally, there was a high-grade lesion in the V4 segment of the left vertebral artery with complete occlusion of the right VA and insufficient collateralization of the posterior circulation through the hypoplastic posterior communicating arteries $(n=1,1.8 \%)$.

Of the 45 symptomatic lesions, exact date of symptom onset was available in 44 cases $(97 \%)$. Average number of days between symptom onset and treatment was $63 \pm 27$ (standard error of mean); the shortest pretreatment period was 0 days (i.e., treatment performed on the day of symptoms onset) and the longest period was 1,130 days.

The severity of the stenoses was 50-69\% in $29(54 \%)$ and $>70 \%$ in $25(46 \%)$ of the lesions. The average degree of the target stenoses was determined as $69.4 \pm 1 \%$ before and $30 \pm 2 \%$ after the treatment. In five cases (9\%), residual stenoses from 56-62\% were seen on the final postinterventional angiogram. A summary of lesion characteristics is given in Table 1 .

Predilatation using a smaller diameter (1.0-1.5 mm) conventional PTCA balloon (Ryujin Plus, Terumo) was performed in 13 cases (24\%). Angioplasty using the SeQuent Please DEB was attempted in 51 (94\%) cases and was successful in 39 cases, giving a $24 \%$ failed-attempt rate. Successful angioplasty with the Dior DEB could be performed in five of six attempted cases, giving a $16 \%$ percent failure rate. Three of the six attempts using the Dior DEB were done as a second attempt following the failure of the SeQuent Please DEB. Overall, successful angioplasty using a DEB could be performed in $44(81 \%)$ cases. In the remaining ten $(19 \%)$ cases, difficult anatomy combined with the shaft thickness and the rigidity of the DEB-tip precluded the insertion of the DEBs
Table 1 Lesion distribution and characteristics

\begin{tabular}{lcc}
\hline Lesion location & $50-70 \% />70 \%[n(\%)]$ & $\begin{array}{l}\text { Asymptomatic/symptomatic/ } \\
\text { multivessel disease }[n(\%)]\end{array}$ \\
\hline ICA extradural & $2 / 0(100 / 0)$ & $1 / 0 / 1(50 / 0 / 50)$ \\
ICA intradural & $2 / 3(40 / 60)$ & $1 / 4 / 0(20 / 80 / 0)$ \\
MCA & $7 / 6(54 / 46)$ & $3 / 10 / 0(23 / 77 / 0)$ \\
VA/V4 & $7 / 11(40 / 60)$ & $0 / 16 / 2(0 / 90 / 10)$ \\
BA & $11 / 5(68 / 32)$ & $1 / 15 / 0(7 / 93 / 0)$ \\
Overall & $29 / 26(53 / 47)$ & $6 / 46 / 3(11 / 83 / 6)$ \\
\hline
\end{tabular}



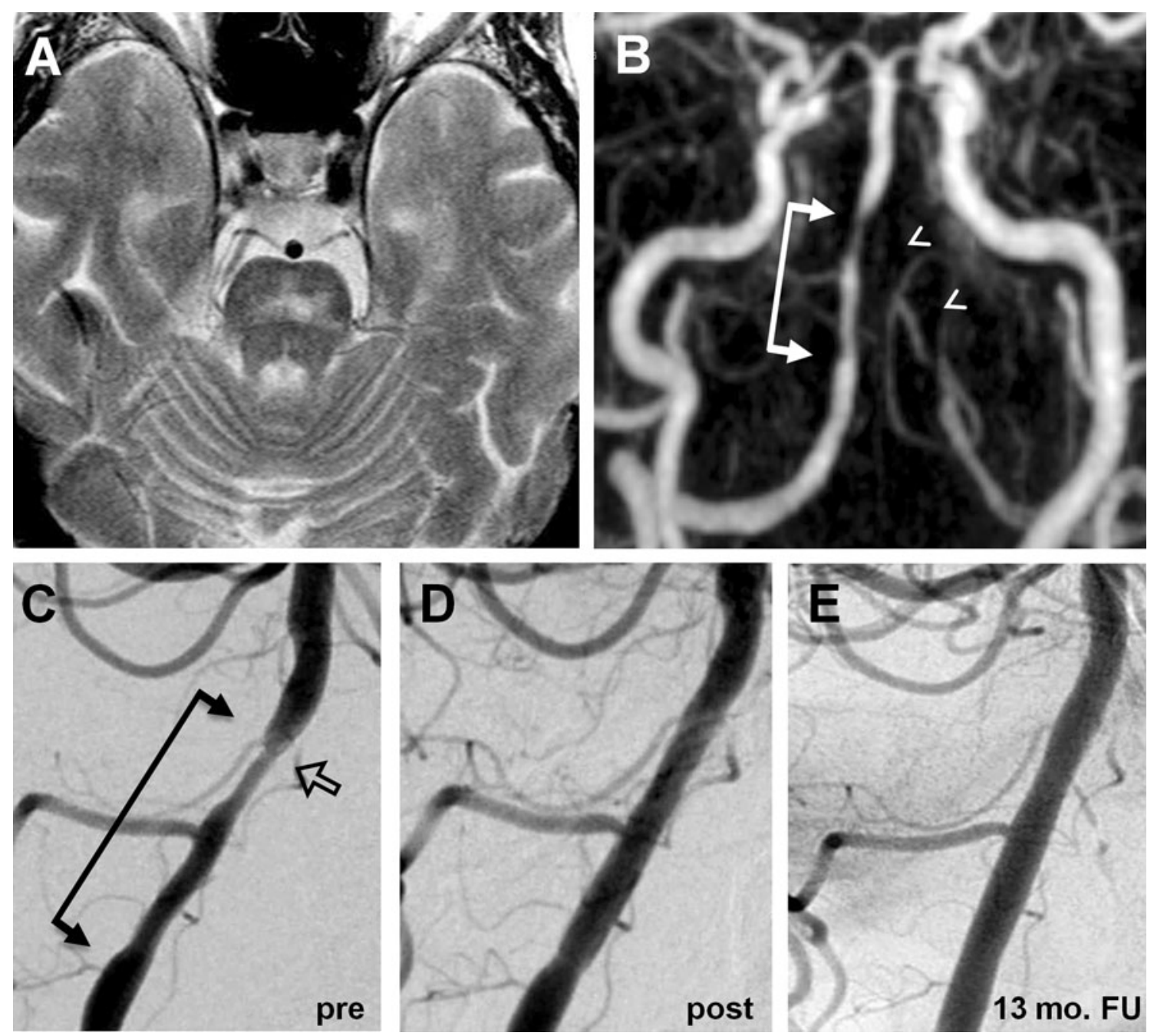

Fig. 1 Endovascular treatment and follow-up of a high-grade, longsegment, vertebro-basilar stenotic lesion in a 67-year-old male patient presenting with infarction in the pons (A). TOF angiogram revealed a long, high-grade stenotic lesion in the middle and distal V4 segment of the right VA and the proximal BA (B, connected arrows) and the chronic occlusion of the distal V4 segment of the left VA (B, arrowheads). The long, high-grade lesion on the right side (C, connected arrows; the open arrow denotes the punctum maximum of the lesion with a $70 \%$ reduction in luminal diameter) has been treated by angioplasty using a SeQuent Please DEB followed by the implantation of a self-expanding Enterprise stent (D). The angiographic follow-up 13 months after the procedure showed a completely patent right V4 segment without signs of neointimal hyperplasia (E). The patient did not show any recurrent symptoms during the follow-up period

hemorrhage around the stented vessel segment, and asymptomatic small petechiae in the basal ganglia were seen on the routinely performed postprocedural CT or MRI scans.

Overall, the procedure-related neurological morbidity and mortality at 30 days and beyond was $5 \%$ (3/54). The nature and clinical course of the complications are given in detail in Table 2.

Subgrouping symptomatic lesions based on the occurrence of adverse events revealed a trend of an inverse correlation between the probability of procedure-related adverse events and the time elapsed between symptom onset and treatment, with average days-to-treatment values of $81 \pm 37$ days and $13 \pm 5$ days in the no complication and the adverse events in four $(7 \%)$ cases. In another four cases $(7 \%)$, clinically silent DWI lesions, asymptomatic minor subarachnoidal 
Table 2 Clinical and technical details of the periprocedural complications

\begin{tabular}{|c|c|c|c|c|c|c|c|c|c|}
\hline \multirow[t]{2}{*}{ Patient } & \multirow[t]{2}{*}{ Age } & \multirow[t]{2}{*}{ Gender } & \multirow{2}{*}{$\begin{array}{l}\text { Indication } \\
\text { for stent- } \\
\text { PTA }\end{array}$} & \multirow[t]{2}{*}{$\begin{array}{l}\text { Lesion } \\
\text { location }\end{array}$} & \multicolumn{2}{|c|}{$\begin{array}{l}\text { Angiographic stenosis } \\
\text { grade }(\%)\end{array}$} & \multirow{2}{*}{$\begin{array}{l}\text { Major } \\
\text { complication with } \\
\text { neurological } \\
\text { morbidity/ } \\
\text { mortality beyond } \\
30 \text { days }\end{array}$} & \multirow{2}{*}{$\begin{array}{l}\text { Minor } \\
\text { complication } \\
\text { with transient } \\
\text { neurological } \\
\text { symptoms }\end{array}$} & \multirow{2}{*}{$\begin{array}{l}\text { Clinically silent } \\
\text { peri-procedural } \\
\text { complications }\end{array}$} \\
\hline & & & & & pretreatment & posttreatment & & & \\
\hline 1 & 71 & $\mathrm{~m}$ & Stroke & $\begin{array}{l}\text { Intradural } \\
\text { VA }\end{array}$ & 79 & 56 & $\begin{array}{l}\text { New infarction of } \\
\text { the dorsolateral } \\
\text { medulla, } \\
\text { permanent deficit }\end{array}$ & - & - \\
\hline 2 & 73 & $\mathrm{~m}$ & TIA & BA & 62 & 9 & $\begin{array}{l}\text { New infarction in } \\
\text { the pons, } \\
\text { permanent deficit }\end{array}$ & - & - \\
\hline 3 & 73 & $\mathrm{~m}$ & Stroke & BA & 61 & 5 & $\begin{array}{l}\text { Reinfarction in the } \\
\text { pons, permanent } \\
\text { deficit, exitus }\end{array}$ & - & - \\
\hline 4 & 76 & $\mathrm{f}$ & Stroke & MCA & 83 & 27 & - & $\begin{array}{l}\text { Two small } \\
\text { lacunae in } \\
\text { ACA area }\end{array}$ & - \\
\hline 5 & 74 & $\mathrm{f}$ & TIA & MCA & 53 & 28 & - & $\begin{array}{l}\text { BG ischemia } \\
2 \text { days later, } \\
\text { clopidogrel } \\
\text { resistance }\end{array}$ & - \\
\hline 6 & 80 & $\mathrm{~m}$ & TIA & MCA & 72 & 39 & - & $\begin{array}{l}\text { New } \\
\text { subcortical } \\
\text { DWI lesion } \\
\text { bilateral }\end{array}$ & - \\
\hline 7 & 73 & $\mathrm{f}$ & Stroke & BA & 72 & 17 & - & $\begin{array}{l}\text { Small DWI } \\
\text { lesions in } \\
\text { pons }\end{array}$ & - \\
\hline 8 & 57 & $\mathrm{~m}$ & TIA & $\begin{array}{l}\text { Intradural } \\
\text { VA }\end{array}$ & 61 & 21 & - & - & $\begin{array}{l}\text { Small DWI lesions } \\
\text { in cerebellum }\end{array}$ \\
\hline 9 & 73 & $\mathrm{f}$ & Stroke & $\begin{array}{l}\text { Intradural } \\
\text { ICA }\end{array}$ & 57 & 19 & - & - & $\begin{array}{l}\text { SAH around stented } \\
\text { ICA segment }\end{array}$ \\
\hline 10 & 66 & $\mathrm{~m}$ & $\begin{array}{l}\text { Silent } \\
\text { infarct }\end{array}$ & BA & 75 & 20 & - & - & $\begin{array}{l}\text { Small DWI lesion in } \\
\text { pons }\end{array}$ \\
\hline 11 & 66 & $\mathrm{f}$ & Stroke & $\begin{array}{l}\text { Intradural } \\
\text { ICA }\end{array}$ & 75 & 20 & - & - & $\begin{array}{l}\text { Stent thrombus during } \\
\text { the intervention, } \\
\text { immediately } \\
\text { recanalized, small } \\
\text { petechiae in BG }\end{array}$ \\
\hline
\end{tabular}

PTA percutaneous transluminal angioplasty, ICA internal carotid artery, $M C A$ middle cerebral artery, VA vertebral artery, $B A$ basilar artery, $T I A$ transient ischemic attack, $B G$ basal ganglia, $D W I$ diffusion weighted imaging, $S A H$ subarachnoid hemorrhage

group, respectively, although analysis of variance failed to show a statistical significance between the two groups (ANOVA, $P=0.27$ ). Further analysis of the relation between treatment timing and adverse events rate showed that $6 / 12$ (50\%) of all adverse events occurred in treatments performed during the first week and 11/12 (92\%) of all adverse events occurred in treatments performed during the first month after symptoms onset.

Angiographic and clinical follow-up examinations were obtained in $33(61 \%)$ of the lesions in 32 patients.
The average follow-up period was 8.9 months, and the longest follow-up period was 16 months. Recurrent stenosis defined as an in-stent stenotic lesion of more than $50 \%$ lumen loss on the follow-up digital subtraction angiography (DSA) series was seen in 1 of the 33 lesions with DSA follow-up (3\%). The asymptomatic in-stent recurrent stenotic lesion developed in the M1 segment of a left MCA 3 months after the angioplasty with a DIOR DEB and implantation of an Enterprise stent. Stent migration was not observed in this series. 


\section{Discussion}

Although percutaneous angioplasty and stent implantation for intracranial atherosclerotic stenotic disease is a widely performed therapeutic option, procedural safety, technical difficulties, and the high rate of recurrent in-stent lesions remain a problem. The importance of these issues and the impact of ICAD are well reflected in the public attention and emerging professional debate, sparked by the recent publication of the SAMMPRIS trial [3, 4]. The results in the endovascular arm of this trial are surprisingly disappointing: $6.7 \%$ technical failure rate, $14.7 \%$ stroke and death rate within 30 days, with the majority $(75 \%)$ of these strokes occurring within 1 day after the procedure as procedural complication, and a projected 1-year stroke and death rate of $20 \%$ [3]. Moreover, as the current SAMMPRIS publication does not report the in-stent recurrence (ISR) rates, the final results may be even worse, considering the reported high ISR rates of self-expanding bare metal stents (24-31\%) [5, 7].

The recently published experience with the treatment of 209 intracranial stenotic lesions using conventional balloon angioplasty followed by the implantation of a selfexpanding bare metal stent (Enterprise, Codman \& Shurtleff) shows very good procedural feasibility with $100 \%$ technical success rate and acceptable procedural safety with $0.9 \%$ procedure-related morbidity and mortality at 30 days and beyond, however, with a rather discouraging ISR rate of $24 \%$ [7]. In another group of patients with 106 high-grade intracranial stenotic lesions treated with a drugeluting coronary stent (DES), a substantially lower recurrence rate of $3.8 \%$ could be achieved with an acceptable procedural complication rate of $0.9 \%$. Stent, balloon, and catheter flexibility of the DES remain to be improved, as $7 \%$ of the attempted interventions failed due to the rigidity of the entire system [6].

Encouraging results with the treatment of intracranial ISR lesions have been reported, using a paclitaxel-eluting PTCA balloon (DEB) [8]. Thus, the rationale behind the present series was to combine the technical ease and procedural safety of balloon angioplasty followed by stent implantation with the beneficial effect of paclitaxel on the ISR rate by performing the predilatation with a DEB.

The results are controversial. Although the ISR rate of $3 \%$ after an average 8.9 months follow-up period is very encouraging and the $5 \%$ procedure related permanent neurological morbidity and mortality rate can be regarded as acceptable, the $19 \%$ failed-attempt rate is certainly too high. This is almost three times higher compared with the drug-eluting coronary stents [6], although it should be noted that the proportion of the attempted and technically more challenging intradural lesions was much higher (96\%) in the current than in the DES series (18\%).
The high failure rate can unequivocally be attributed to the rigidity of the balloon shaft and to the stiffness of the balloon tip. The drug-eluting PTCA balloons were originally developed for the coronary vasculature, where maneuvering through elongated, difficult proximal access vessels is rarely an issue. On the other hand, our previous experience with the intracranial application of these balloons in the redilatation of ISR lesions was much more promising with only $6 \%$ failure rate [8].

The physical properties of the two DEBs applied in this study are slightly different. This results partly from the differences in the balloons and partly from the different principles of drug coating. SeQuent Please uses a coating technology, where the bioavailability of paclitaxel is enhanced through the addition of the modified contrast medium molecule iopromide [11], whereas the DIOR PTCA balloon catheter's coating matrix consists of shellac, a natural resin [12]. The number of cases in this study (SeQuent Please: 52, DIOR: 6) does not allow any reasonable conclusion regarding the superiority of one of the above-mentioned coating technologies. Predilatation with a more flexible, smaller diameter conventional balloon facilitates the subsequently attempted advancement of DEB through the stenotic vessel segment; however, it makes the procedure more complicated and technically demanding and adds an additional potential source of complications. We believe that the eventual solution for the access issues would be the development of a more flexible DEB with hydrophilic coating, designed specifically for intracranial vessels. The development of these balloons in the near future would be of great importance, because long, eccentric, high-grade, intracranial, stenotic lesions are difficult to treat; the currently available drug-eluting coronary stents are not suitable for these lesions due to their stiffness, whereas the application of the sufficiently flexible self-expanding, bare-metal stents results in poor recurrence rates. The combination of the self-expanding stents with the DEBs can be safe and efficient in treating this type of lesions (Fig. 1.)

The observed trend of higher probability of periprocedural complications associated with the early treatment of symptomatic lesions with $50 \%$ of all adverse events occurring when treatment was performed during the first week and $92 \%$ of all adverse events occurring when a symptomatic lesion has been treated during the first month after symptoms onset is in accordance with previous observations regarding treatment timing [13, 14]. Possible explanations for the higher periprocedural complication rate observed following early revascularization of a symptomatic, high-grade, intracranial, atherosclerotic lesion include the vulnerability of perforator arteries originating from the stented segment (e.g., M1 segment of the MCA or basilar trunk) and the concept of unstable and 
vulnerable plaque due to inflammatory processes. However, it cannot be excluded that those lesions with preprocedural complications also might be more prone to repeat ischemic events when left untreated.

The procedure-related permanent neurological morbidity and mortality rate of $5 \%$ presented is much better than the recently published $20 \%$ periprocedural complication rate in the endovascular arm of the SAMMPRIS study [3]. It has been long-known that patients treated in highenrollment endovascular centers have significantly lower rates of periprocedural complications compared with low enrollment centers with less than ten intracranial stenting procedures performed yearly, with $5 \%$ versus $29.3 \%$ complication rate in high- and low-volume centers, respectively (14). Calculating the yearly number of intracranial stenting procedures gives 1.9 treatment per center per year in the endovascular arm of the SAMMPRIS study [3] as opposed to 40.5 treatment per center per year in the present study, which we believe is the main reason behind the striking difference in the complication rates.

We are aware of the limitations of the present study. First, a certain bias in patient selection was introduced, because it was based on the experience and discretion of the senior author. Second, data from a retrospective clinical series are certainly more prone to inconsistencies compared with those from a strictly regulated and externally monitored prospective, randomized trial. Third, we did not perform any direct comparison with other treatment methods or devices, such as medical treatment alone, stenting with bare-metal or drug-eluting coronary stents, etc., therefore, the safety and efficacy of the method presented could be compared with historical data only. Fourth, the presented number of cases is rather small compared with larger, multicenter studies. Finally, clinical and angiographic follow-up rate is limited without long-term follow-up data at the present.

\section{Conclusions}

Endovascular treatment of atherosclerotic intracranial stenotic lesions by angioplasty using a drug-eluting balloon followed by the implantation of a self-expanding stent is feasible, relatively safe and results in low recurrence rates. The physical properties of the drug-eluting balloons, however, need to be improved substantially to achieve adequate technical success rates, thereby making this procedure applicable in patients with elongated supra-aortic and intracranial vessels.

Conflict of interest The authors declare that they have no conflict of interest. Open Choice access was sponsored by Codman Neurovascular.

\section{References}

1. Sacco RL, Kargman DE, Gu Q et al (1995) Race-ethnicity and determinants of intracranial atherosclerotic cerebral infarction. The Northern Manhattan Stroke Study. Stroke 26:14-20

2. Chimowitz MI, Lynn MJ, Howlett-Smith H et al (2005) Comparison of warfarin and aspirin for symptomatic intracranial arterial stenosis. N Engl J Med 352:1305-1316

3. Chimowitz MI, Lynn MJ, Derdeyn CP et al (2011) Stenting versus aggressive medical therapy for intracranial arterial stenosis. N Engl J Med 365:993-1003

4. Henkes H, Bäzner H, Nelson PK (2011) Comment on: Stenting versus aggressive medical therapy for intracranial arterial stenosis: Chimowitz MI, Lynn MJ, Derdeyn CP et al. N Engl J Med 365:993-1003. Clin Neuroradiol 21:257-259

5. Turk AS, Levy EI, Albuquerque FC et al (2008) Influence of patient age and stenosis location on wingspan in-stent restenosis. AJNR Am J Neuroradiol 29:23-27

6. Vajda Z, Aguilar M, Göhringer T, Horváth-Rizea D, Bäzner H, Henkes H (2012) Treatment of intracranial atherosclerotic disease with a balloon-expandable paclitaxel eluting stent: procedural safety, efficacy and mid-term patency. Clin Neuroradiol [Epub ahead of print]

7. Vajda Z, Schmid E, Güthe T et al (2012) The modified Bosemethod for the endovascular treatment of intracranial atherosclerotic arterial stenoses using the Enterprise stent. Neurosurgery 70:91-101

8. Vajda Z, Güthe T, Perez MA et al (2011) Neurovascular in-stent stenoses: treatment with conventional and drug-eluting balloons. AJNR Am J Neuroradiol 32:1942-1947

9. Man BL, Fu YP, Chan YY et al (2009) Lesion patterns and stroke mechanisms in concurrent atherosclerosis of intracranial and extracranial vessels. Stroke 40:3211-3215

10. Kim YD, Choi HY, Jung YH et al (2009) Mirror pattern of cerebral artery atherosclerosis in patients with ischaemic stroke. Eur J Neurol 16:1159-1164

11. SeQuent ${ }^{\circledR}$ Please Brochure. http://www.aesculap-extra.net/public/ frame_doc_index.html?med_id=1000019569. Accessed 31 Jan 2012

12. DIOR ${ }^{\circledR}$ product information. http://www.eurocor.de/products/dior/ product_information/last. Accessed 31 Jan 1012

13. Bose A, Hartmann M, Henkes $H$ et al (2007) A novel, selfexpanding, nitinol stent in medically refractory intracranial atherosclerotic stenoses. The WingSpan Study. Stroke 38:15311537

14. Nahab F, Lynn MJ, Kasner SE et al (2009) Risk factors associated with major cerebrovascular complications after intracranial stenting. NIH Multicenter Wingspan Intracranial Stent Registry Study Group. Neurology 72:2014-2019 